\title{
Knowledge and Attitudes towards Dementia among Clinical Years Medical Students at Jazan University: A Cross-sectional Study
}

\author{
Mona H. Elmahdy ${ }^{1}$, Maryam E. Ajeebi ${ }^{2}$, Arwa A. Hudisy ${ }^{2}$ Jnadi M. Madkhali ${ }^{* 2}$, Athar M. Madkhali ${ }^{2}$, \\ Ammar A. Hakami ${ }^{2}$ \\ ${ }^{1}$ Public Health Consultant, Professor, Family and Community Medicine Department, College of Medicine, \\ Jazan University, P.O Box 114, Jazan, Saudi Arabia \\ ${ }^{2}$ Medical Intern, Jazan University, P.O Box 114, Jazan, Saudi Arabia \\ *Corresponding author: Jnadi M. Madkhali; Jnady888@gmail.com
}

Received 02 February 2020;

Accepted 23 February 2020;

Published 27 February 2020

\begin{abstract}
Background: The literature suggests that training in dementia among medical students appears to be inadequate. This study aimed to evaluate medical students' knowledge and attitudes toward dementia. Aim: To assess knowledge and attitudes of Saudi medical students towards dementia. Methods: This cross-sectional study was conducted at College of Medicine, Jazan University, Jazan, Saudi Arabia using a sample of 241 medical students from clinical years (4th, 5th, and 6th). A structured and self-assessment questionnaire was used and included the sociodemographic data and questions related to knowledge and attitudes toward dementia. Data were presented as frequency and percentage, and as mean and standard deviation (SD). Results: A total of 241 participants agreed to take part in our study; 155 (64.3\%) of them were females. Only $44(18.3 \%)$ participants stated that they had a good training in dementia (mostly theoretical, 16.6\%) and 17 (7.1\%) mentioned having an extracurricular course in the subject. Out of 14 questions, participants obtained a mean of 1.49 ( $\mathrm{SD}=1.48)$. Regarding attitudes, participants agreed that much can be done to improve the quality of life of patients with dementia and their caregivers, that it is useful to provide the diagnosis of dementia to the family, and that dementia is better diagnosed in specialized service units. Conclusions: The findings of the present study suggest that while medical students generally have positive attitudes toward dementia, they have poor knowledge about the subject. More effort is needed to bridge knowledge gaps in dementia understanding at undergraduate level.
\end{abstract}

Keywords: Knowledge, Attitudes, Dementia, Medical students, Saudi Arabia.

\section{Introduction}

Dementia is a common and incapacitating syndrome with huge impact on patients and societies. It represents a wide variety of neurological, psychiatric and medical conditions with significant impairment in cognitive abilities that interfere with everyday life ${ }^{[1]}$. Globally, 47 million people were estimated to be suffering from dementia in 2015, and they are projected to reach 75 million by 2030 and 135 million by $2050{ }^{[2]}$. Regionally, the proportion of Saudi population living with dementia represents the upper range compared to developing and developed countries ${ }^{[3]}$. It is noteworthy that the age of Saudis is shifting towards elderly which is expected to represent $25 \%$ of the total population by 2050 . These trends should direct our attention to applying strategies for dementia prevention given the mounting evidence on the role of multifactorial intervention in dementia prevention ${ }^{[3]}$.
As per NICE/SCIE guidelines [National Collaborating Centre for Mental Health (UK), 2007], there is a need to improve awareness, skills and attitudes of health professionals responsible for taking care of people with dementia. Increasing public understanding of dementia is also recommended to make communities more "dementia-friendly", ${ }^{[4]}$. The role of a dementiafriendly community is to strengthen the relationship between people with dementia and their caretakers so that they can actively participate in decision-making process ${ }^{[5]}$, helping them to remain independent and to be enable to have control on their lives as long as they can ${ }^{[6]}$.

Improving young adults' knowledge and attitudes toward dementia is particularly important given the ever increasing susceptibility to the disease. Therefore, educating young people about dementia in schools is on way into achieving this in a standardized manner. Internationally, nursing and medical students generally carry positive attitudes toward people with dementia ${ }^{[7,8]}$, 
although the depth of knowledge of these students is still concerning ${ }^{[7,9]}$. One study of final year medical students in Brazil found that students had only theoretical knowledge in dementia and lack practical training ${ }^{[10]}$.

To the best of our knowledge, little is known about medical students' attitudes and knowledge of dementia in Saudi Arabia. This study aims to evaluate the knowledge and attitudes of medical students towards dementia at a large University in Saudi Arabia. The findings of this study may serve as a paradigm for the local research on the subject.

\section{Materials and methods}

\subsection{Study design, settings and population}

An observational cross-sectional survey was conducted in Jazan University in the academic year 2019. The target subjects were both male and female medical students in the clinical years. According to Jazan University curriculum, clinical years in the college of medicine are the $4^{\text {th }}, 5^{\text {th }}$, and $6^{\text {th }}$ years. Medical students were recruited through social media and invited to participate in the survey. Included in the study were all clinical years medical students who accepted to fill the study questionnaire. A sample of 241 students was calculated using a 95\% confidence level, 5\% margin of error and assuming a previous prevalence of $50 \%$ because there is no prior data on the subject in Jazan region.

\subsection{Data Collection and quality control}

Data were collected using Arabic, structured, and self-assessment questionnaire consisted of 30 questions presented in three parts. The questionnaire was adopted from a previous study on Brazilian medical students ${ }^{[10]}$. Respondents were firstly asked about some socio-demographic details including age, sex, year of study and any previous training in dementia. The remaining items of the questionnaire assessed respondents' knowledge about dementia in 14 questions. The knowledge section included questions on the epidemiology, diagnosis and management of people with dementia. Finally, respondents' attitudes toward people with dementia were assessed using 10 a 5-responses Likert scale (Strongly agree, agree, neutral, disagree, and strongly disagree).

\subsection{Data management and analysis}

The questionnaire papers were verified and entered at home and then merged into one device. Categorical variables were described by frequencies and percentages, while numerical variables were presented as a mean and standard deviation. Associations were considered statistically significant if $p>0.05$. The analysis was conducted using Statistical Package of Social Sciences (SPSS) Version 20 (SPSS Inc., Chicago, IL).

\subsection{Ethical consideration}

Our study was conducted in accordance with the ethical standards of the Kingdom of Saudi Arabia. A verbal consent was obtained from all the participants after a prior orientation regarding the objectives and benefits of the project. Participants then read, understood and answered the questions accordingly. They have been told that they have all rights to participate and their information will be kept anonymous and confidential. The study ethical clearance was obtained from Ethical Committee at Jazan University.

\section{Results}

A total of 241 participants (88.9\%) agreed to take part in this study; $155(64.3 \%)$ of them were females. The final sample consisted of clinical years medical students; $113(46.9 \%)$ from the 4th year, 95 (39.4\%) from the 5 th year, and $33(13.7 \%)$ from the 6 th year. Regarding the questions about having a good training in cognitive impairments, only 44 (18.3\%) students responded positively and 17 $(7.1 \%)$ mentioned having an extracurricular course in the subject of dementia. Of the 55 students responded to the question regarding the type of training, $40(16.6 \%)$ had a theoretical training and 15 (6.2\%) had both theoretical and practical training. Table 1 describing the Sociodemographic characteristics of the study participants.

Table 1: Sociodemographic characteristics of study participants $(\mathrm{N}=\mathbf{2 4 1})$

\begin{tabular}{|l|l|}
\hline Sociodemographic characteristics & $n(\%)$ \\
\hline Sex & $86(35.7)$ \\
\hline Male & $155(64.3)$ \\
\hline Female & $113(46.9)$ \\
\hline Year of study & $95(39.4)$ \\
\hline $4^{\text {th }}$ & $33(13.7)$ \\
\hline $5^{\text {th }}$ & \\
\hline $6^{\text {th }}$ & $44(18.3)$ \\
\hline Did you have good training in cognitive alterations? & $197(81.7)$ \\
\hline Yes & $21(15.9)$ \\
\hline No + do not remember & $17(7.1)$ \\
\hline Have you taken any extracurricular courses on the subject? & $224(92.9)$ \\
\hline Yes & \\
\hline No + do not remember & $40(16.6)$ \\
\hline If yes, the training in cognitive alterations was: & $15(6.2)$ \\
\hline Theoretical & \\
\hline Theoretical and practical & \\
\hline${ }^{*}$ The total percentage does not add to 100\% because of missing values. & \\
\hline
\end{tabular}

Table 2 displays subjects' correct responses to the knowledge questionnaire. Only questions 2 and 3 revealed a higher percentage of correct answers. The subjects obtained a mean score of 1.49 ( $\mathrm{SD}=1.48)$ in the knowledge questionnaire out of a total scoring scale of 14 points. These results indicate a generally poor knowledge about cognitive alterations in dementia among the study subjects (Appendix A). 
Table 2: Correct answers in the knowledge questionnaire

\begin{tabular}{|c|c|c|}
\hline \multicolumn{2}{|l|}{ Questions } & $\begin{array}{l}\text { Correct } \\
\text { answer } n(\%)\end{array}$ \\
\hline \multirow[t]{3}{*}{ Epidemiology } & $\begin{array}{l}\text { 1. General clinic with a list of } 1,000 \text { persons aged } 60 \text { years or older must wait to have the following } \\
\text { approximate number of persons with dementia on this list: }\end{array}$ & $45(18.7)$ \\
\hline & 2. Starting from 65 years of age, the prevalence of dementia is: & $105(43.6)$ \\
\hline & 3. One of the risk factors for developing Alzheimer's disease is: & $168(69.7)$ \\
\hline \multirow[t]{8}{*}{ Diagnosis } & 4. All of the following are potentially treatable etiologies of dementia, except: & $67(27.8)$ \\
\hline & 5. Patients with suspected dementia must be evaluated as soon as possible, since: & $35(14.5)$ \\
\hline & $\begin{array}{l}\text { 6. Which of the following procedures is necessary to confirm definitively that the symptoms } \\
\text { are caused by dementia? }\end{array}$ & $6(2.5)$ \\
\hline & $\begin{array}{l}\text { 7. Which of the alternatives is not necessary in the initial evaluation of a patient with } \\
\text { suspected dementia? }\end{array}$ & $43(17.8)$ \\
\hline & 8. Which of these alternatives can resemble dementia? & $33(13.7)$ \\
\hline & $\begin{array}{l}\text { 9. When a patient presents a sudden onset of confusion, disorientation and incapacity to maintain } \\
\text { attention, this clinical picture is more compatible with a diagnosis of: }\end{array}$ & $36(14.9)$ \\
\hline & 10. Which of the following options is almost always present in dementia? & $16(6.6)$ \\
\hline & $\begin{array}{l}\text { 11. Which of the following clinical findings best differentiate vascular dementia from the dementia of } \\
\text { Alzheimer's disease? }\end{array}$ & $29(12.0)$ \\
\hline \multirow[t]{3}{*}{ Management } & 12. The effect of anti-dementia medications act on: & $24(10.0)$ \\
\hline & 13. Which statement on the treatment of demented patients with depression is true? & $4(1.7)$ \\
\hline & $\begin{array}{l}\text { 14. For what purpose does the ABRAZ Brazilian association supply information to patients and } \\
\text { caretakers? }\end{array}$ & $47(19.5)$ \\
\hline
\end{tabular}

\begin{tabular}{|c|c|c|}
\hline \multicolumn{3}{|l|}{ Appendix A: Correct answers in the knowledge questionnaire } \\
\hline \multirow{2}{*}{ Question } & \multicolumn{2}{|c|}{ Correct answer } \\
\hline & Count & Percentage \% \\
\hline $\begin{array}{l}\text { 1. A general practitioner with a list of } 1,500-2,000 \text { persons aged } 60 \text { years or older can expect to have the } \\
\text { following number of people with dementia on their list : }\end{array}$ & 35 & 17.59 \\
\hline 2. $\quad$ Starting from 65 years of age, the prevalence of dementia is : & 108 & 54.27 \\
\hline 3. One of the risk factors for the development of Alzheimer's disease is : & 150 & 75.38 \\
\hline 4. All of the following are potentially treatable etiologies of dementia except : & 99 & 49.75 \\
\hline 5. Patients with suspected dementia must be evaluated as soon as possible as: & 57 & 28.64 \\
\hline 6. Which of the following procedures is required to definitely confirm that symptoms are due to dementia? & 19 & 9.55 \\
\hline $\begin{array}{l}\text { 7. Which of the following alternatives is not a necessary part of the initial evaluation of a patient with possible } \\
\text { dementia? }\end{array}$ & 86 & 43.22 \\
\hline 8. Which of the following alternatives can resemble dementia? & 4 & 2.01 \\
\hline $\begin{array}{l}\text { 9. When a patient develops a sudden onset of confusion, disorientation, and inability to sustain attention, this } \\
\text { presentation is most consistent with the diagnosis of : }\end{array}$ & 65 & 32.66 \\
\hline 10. Which of the following is almost always present in dementia? & 39 & 19.60 \\
\hline $\begin{array}{l}\text { 11. Which of the following clinical findings best differentiates vascular dementia from dementia of Alzheimer's } \\
\text { disease? }\end{array}$ & 94 & 47.24 \\
\hline 12. The effect of anti-dementia drugs is to : & 48 & 24.12 \\
\hline 13. Which statement is true concerning the treatment of dementia patients who are depressed? & 38 & 19.10 \\
\hline 14. Which of the following best describes the functions of the Alzheimer's Disease Society? & 94 & 47.24 \\
\hline
\end{tabular}

According to Table 3, the majority of students agreed that much can be done to improve the quality of life of patients with dementia and their caregivers. Also, the majority agreed that it is useful to provide the diagnosis of dementia to the family and that dementia is better diagnosed in specialized service units (Appendix B).

Table 3: Distribution of students' attitudes towards dementia

\begin{tabular}{|c|c|c|c|c|c|}
\hline Attitudes & $\begin{array}{c}\text { Strongly } \\
\text { agree }\end{array}$ & Agree & Neutral & Disagree & $\begin{array}{l}\text { Strongly } \\
\text { disagree }\end{array}$ \\
\hline $\begin{array}{l}\text { 1. Much can be done to improve the quality of life of caregivers of } \\
\text { persons with dementia }\end{array}$ & $77(32.0)$ & $92(38.2)$ & $60(24.9)$ & $7(2.9)$ & $5(2.1)$ \\
\hline $\begin{array}{l}\text { 2. The families prefer to be informed about the dementia of their } \\
\text { relative as rapidly as possible }\end{array}$ & $94(39.0)$ & $2(0.8)$ & $88(36.5)$ & $44(18.3)$ & $5(2.1)$ \\
\hline $\begin{array}{l}\text { 3. Much can be done to improve the quality of life of persons with } \\
\text { dementia }\end{array}$ & $80(33.2)$ & $96(39.8)$ & $48(19.9)$ & $13(5.4)$ & $4(1.7)$ \\
\hline $\begin{array}{llllll}\text { 4. } & \begin{array}{l}\text { Providing the diagnosis } \\
\text { useful than harmful }\end{array} & \text { is } & \text { generally } & \text { more } \\
\end{array}$ & $90(37.3)$ & $83(34.4)$ & $54(22.4)$ & $8(3.3)$ & $6(2.5)$ \\
\hline 5. Dementia is better diagnosed in specialized service units & $73(30.0)$ & $79(32.8)$ & $74(30.7)$ & $8(3.3)$ & $7(2.9$ \\
\hline $\begin{array}{l}\text { 6. The patients with dementia can drain resources with little positive } \\
\text { result }\end{array}$ & $17(7.1)$ & $46(19.1)$ & $132(54.8)$ & $32(13.3)$ & $14(5.8)$ \\
\hline 7. It is better to speak with the patient utilizing euphemisms & $18(7.5)$ & $100(41.5)$ & $99(41.1)$ & $10(4.1)$ & $14(5.8)$ \\
\hline
\end{tabular}




\begin{tabular}{|ll|c|c|c|c|c|}
\hline 8. & Treating dementia tends to be more frustrating than gratifying & $17(7.1)$ & $43(17.8)$ & $120(49.8)$ & $39(16.2)$ & $22(9.1)$ \\
\hline 9. & $\begin{array}{l}\text { Directing families to specialized services is not worth the effort } \\
\text { when they do not want to use them }\end{array}$ & $22(9.1)$ & $59(24.5)$ & $110(45.6)$ & $35(14.5)$ & $15(6.2)$ \\
\hline $\begin{array}{l}\text { 10. } \\
\text { The primary care team has a very limited role in the care of persons } \\
\text { with dementia }\end{array}$ & $39(16.2)$ & $69(28.6)$ & $82(34.0)$ & $37(15.4)$ & $14(5.8)$ \\
\hline
\end{tabular}

\begin{tabular}{|c|c|c|c|c|c|c|}
\hline \multirow{2}{*}{ Attitudes } & \multicolumn{2}{|c|}{ Agree } & \multicolumn{2}{|c|}{ Neutral } & \multicolumn{2}{|c|}{ Disagree } \\
\hline & Count & $\begin{array}{c}\text { Percentage } \\
\%\end{array}$ & Count & $\begin{array}{l}\text { Percentage } \\
\quad \%\end{array}$ & Count & $\begin{array}{l}\text { Percentage } \\
\%\end{array}$ \\
\hline $\begin{array}{l}\text { Much can be done to improve the quality of life of caregivers of } \\
\text { persons with dementia? }\end{array}$ & 91 & $45.70 \%$ & 32 & $16.10 \%$ & 76 & $38.20 \%$ \\
\hline $\begin{array}{l}\text { The families prefer to be informed about the dementia of their } \\
\text { relative as rapidly as possible? }\end{array}$ & 175 & $87.90 \%$ & 20 & $10.10 \%$ & 4 & $2 \%$ \\
\hline $\begin{array}{l}\text { Much can be done to improve the quality of life of persons with } \\
\text { dementia? }\end{array}$ & 159 & $79.90 \%$ & 37 & $18.60 \%$ & 3 & $1.50 \%$ \\
\hline $\begin{array}{l}\text { Providing the diagnosis of dementia is usually more helpful than } \\
\text { harmful? }\end{array}$ & 163 & $81.90 \%$ & 32 & $16.10 \%$ & 4 & $2 \%$ \\
\hline Dementia is better diagnosed in specialized service units? & 124 & $62.30 \%$ & 66 & $33.20 \%$ & 9 & $4.50 \%$ \\
\hline $\begin{array}{l}\text { Patients with dementia can be a drain on resources with little } \\
\text { positive outcome and result? }\end{array}$ & 79 & $39.70 \%$ & 99 & $49.70 \%$ & 21 & $10.60 \%$ \\
\hline It is better to talk to the patient in euphemistic terms? & 71 & $35.70 \%$ & 104 & $52.30 \%$ & 24 & $12.10 \%$ \\
\hline Treating dementia tends to be more frustrating than rewarding? & 59 & $29.60 \%$ & 64 & $32.20 \%$ & 76 & $38.20 \%$ \\
\hline $\begin{array}{l}\text { Directing families to specialized services is not worth the effort } \\
\text { when they don't want to use them? }\end{array}$ & 59 & $29.60 \%$ & 60 & $30.20 \%$ & 80 & $40.20 \%$ \\
\hline $\begin{array}{l}\text { The primary care team has a very limited role to play in the care } \\
\text { of persons with dementia? }\end{array}$ & 75 & $37.70 \%$ & 44 & $22.10 \%$ & 80 & $40.20 \%$ \\
\hline
\end{tabular}

\section{Discussion}

This study aimed to evaluate dementia knowledge and attitudes among medical students in Saudi Arabia.

The results of the present study suggest that medical students have a poor level of knowledge about dementia. The proportion of correct responses did not exceed $25 \%$ in all parts of knowledge section. Whilst it could be argued that knowing certain items (e.g. the role of Alzheimer's Disease Society) is neither essential nor expected, it is noteworthy that a large proportion of participants were unable to correctly answer more basic questions, e.g. etiology of dementia ( $72.2 \%$ incorrect), diagnosis confirmation (97.5\% incorrect), and the role of anti-dementia medications (98.3\%). We also argue that the subjects' poor knowledge about dementia cannot be attributed to the nature of questionnaire and difficulty of questions. Another study which used the same items showed that almost 50\% medical students correctly answered knowledge questions ${ }^{[10]}$. Furthermore, these findings could be reasonably attributed to educational gaps in students' training, an explanation supported by the finding that $81.7 \%$ of participants denied having any training in dementia and $92.9 \%$ denied having any extracurricular courses in the subject.

Participants showed generally positive attitudes, confirming previous findings that medical students have generally positive attitudes toward dementia ${ }^{[7,8,10]}$. However, there are still areas to improve, e.g. almost a quarter (24.9\%) agreed that "Treating dementia tends to be more frustrating than gratifying".

The main limitation of the present study is the use of a nonvalidated measure of knowledge and attitudes of dementia. Whilst the items were adopted from an established questionnaire ${ }^{[10]}$, the fact that the measure was not specifically designed for the current sample could influence participants' responses, either in wording or the responses. The self-administered questionnaire will also influence how the present findings are compared to other findings; however the items were already made available in this study for future comparisons on individual items.

\section{Conclusion and recommendation}

This study provides evidence of knowledge gaps in the subject of dementia, but it shows generally positive attitudes toward dementia in Saudi medical students. Future studies are recommended to find out whether these findings are unique to the present sample, and if not, what are the most effective methods of promoting knowledge and attitudes toward dementia in medical students in general. Ensuring that education in dementia constitutes a part of the curriculum will help in increasing students' awareness of the disease.

\section{Data Availability Statement}

The data used to support the findings of this study is available from the corresponding author upon request.

\section{Conflicts of interest}

The authors declare they have no conflicts of interest.

\section{Acknowledgment}

Financial support and sponsorship: This study received support and funding from the Deanship of Scientific Research, Jazan University, Jazan, KSA Funding number FR6-118

\section{References}

[1] Winblad B, Amouyel P, Andrieu S, et al. "Defeating Alzheimer's disease and other dementias: a priority for 
European science and society," Lancet Neurol, vol. 15, no. 5, pp. 455-532, 2016.

https://www.ncbi.nlm.nih.gov/pubmed/26987701

[2] Prince M, Ali GC, Guerchet M, et al. "Recent global trends in the prevalence and incidence of dementia, and survival with dementia," Alzheimers Res Ther, vol. 8, no. $1, \quad$ pp. 23, 2016. https://www.ncbi.nlm.nih.gov/pubmed/27473681

[3] Alkhunizan M, Alkhenizan A, Basudan L. "Prevalence of Mild Cognitive Impairment and Dementia in Saudi Arabia: A Community-Based Study," Dement Geriatr Cogn Dis Extra, vol. 8, no. 1, pp. 98-103, 2018. https://www.ncbi.nlm.nih.gov/pubmed/29706986

[4] Isaac MGEKN, Isaac MM, Farina N, et al. "Knowledge and attitudes towards dementia in adolescent students," J Ment Health, vol. 26, no. 5, pp. 419-425, 2017. https://www.ncbi.nlm.nih.gov/pubmed/27809625

[5] Crampton J, Dean J, Eley R. "Creating a dementiafriendly York," Joseph Rowntree Foundation, 2012. https://www.jrf.org.uk/sites/default/files/jrf/migrated/file s/dementia-communities-york-full.pdf

[6] Prior P. "Knowing the foundations of dementia friendly communities for the North East," North East Dementia Alliance, 2012.
https://www.housinglin.org.uk/_assets/Resources/Housin g/OtherOrganisation/dementiacommunities.pdf

[7] Scerri A, Scerri C. "Nursing students' knowledge and attitudes towards dementia - a questionnaire survey," Nurse Educ Today, vol. 33, no. 9, pp. 962-8, 2013. https://www.ncbi.nlm.nih.gov/pubmed/23182308

[8] Tullo ES, Young TJ. "Medical students' attitudes toward people with dementia: an international investigation," Int psychogeriatrics, vol. 26, no. 1, pp. 165-71, 2014. https://www.ncbi.nlm.nih.gov/pubmed/24135153

[9] Kwok T, Lam K-C, Yip A, et al. "Knowledge of Dementia among Undergraduates in the Health and Social Care Professions in Hong Kong," Soc Work Ment Health, vol. 9, no. 4, pp. 287-301, 2011. https://www.tandfonline.com/doi/abs/10.1080/15332985. 2011.572696

[10] Jacinto AF, Citero VA, Lima JL, et al. "Knowledge and attitudes towards dementia among final-year medical students in Brazil," Rev Assoc Med Bras, vol. 63, no. 4, pp. 366-370, 2017.

https://www.ncbi.nlm.nih.gov/pubmed/28614541 